\title{
Turn on the Mtr pathway genes under pLacl promoter in Shewanella oneidensis MR-1
}

I-Son $\mathrm{Ng}^{1 *}{ }^{*}$, Yanlan Guo ${ }^{2+}$, Yunli Zhou ${ }^{2+}$, Jhe-Wei Wu', Shih-I Tan' ${ }^{1}$ and Ying-Chen Yi ${ }^{1}$

\begin{abstract}
Background: Shewanella genus is famous for applications like electron transfer in microbe fuel cells and bioremediation of heavy metals through the Mtr pathway. A potential way to enhance the electron genesis ability of Shewanella is to express exogenous $m$ tr genes via recombinant DNA technology. Thus, to design and develop expression vectors capable of replicating in Shewanella and enhance the genetic toolbox of the same is important.

Result: In this study, a plasmid construct with a replication origin, repB, and pLacl promoter is reported for the first time to drive the expression of green fluorescent protein in S. oneidensis MR-1. Based on the same vector, the Mtr pathway genes $m t r A, m t r C$, and $m t r C A B$ were also successfully expressed in MR-1. The recombinant strains had higher ferric reductase activity compared to the wild type. The highest enzymatic activity of $508.33 \mathrm{U} / \mathrm{L}$ in genetic Shewanella with mtrC gene is obtained, which is 1.53 -fold higher than that of wild strain. The plasmids were stable up to 90 generations.

Conclusion: We have demonstrated an expression system based on pLacl promoter and repB ori in Shewanella. Consequently, the combination of repB and pLacl will have great potential in Shewanella to turn on expression of different genes constitutively.
\end{abstract}

Keywords: Shewanella, Mtr pathway, Green fluorescent protein, Shuttle vector, Ferric reductase

\section{Background}

In recent years, energy conservation, environmental protection, and circular economics are of great importance in a highly resource-limiting world. As a matter of fact, bioremediation, bioeconomic, and generating energy by waste to electricity are becoming increasingly important (Chen et al. 2013; Chaturvedi and Verma 2016; Ng et al. 2017; Takahashi et al. 2016). Among most of microorganisms used in bioenergies and bioresources, Shewanella genus is the most important dissimilatory metal reducing bacteria (DMRB) which have been widely studied for biodecolorization, bioremediation, microbe fuel cell, and

\footnotetext{
*Correspondence: yswu@mail.ncku.edu.tw

${ }^{\dagger}$ Yanlan Guo and Yunli Zhou contributed equally to this work ${ }^{1}$ Department of Chemical Engineering, National Cheng Kung University, Tainan 70101, Taiwan

Full list of author information is available at the end of the article
}

biofabrication (Bretschger et al. 2007; Jayasinghe et al. 2014; Nealson and Scott 2006; Ng et al. 2014a, b; Wu and Ng 2017). Among all properties, the great interests of Shewanella come from their ability to conduct anaerobic respiration using diverse electron acceptors such as $\mathrm{Fe}(\mathrm{III})$, oxygen, nitrate, and other metals. S. oneidensis MR-1 is a facultative anaerobe, which can reduce several metal ions such as $\mathrm{Mn}(\mathrm{IV})$ and $\mathrm{Fe}(\mathrm{III})$ through the Mtr pathway (Bretschger et al. 2007). The mechanism of electron transfer in Mtr pathway is as follows: the electrons are transferred from the inner-membrane, through the periplasm and across the outer-membrane to the extracellular surface. The protein components for the Mtr pathway include CymA, MtrA, MtrB, MtrC, and OmcA, which are in the sequence omcA-mtrC-mtrA-mtrBcym $A$ in Shewanella genome. The electron-transfer reaction mediated by Mtr pathway has also been applied for biotechnological applications in electro-biosynthesis of 
valuable materials, chemicals or fuels (Shi et al. 2012). Recently, a synthetic electron conduit has been engineered in E. coli by heterologous expression of the Mtr gene from S. oneidensis MR-1 (Jensen et al. 2010). Therefore, to accelerate the function of the electron conduit in Shewanella and how to turn it on efficiently is of utmost importance.

However, studies on molecular and genome of Shewanella are restricted due to lack of effective vectors, expect the pDS3.0 (Yuan et al. 2011). The pDS3.0 is a knock out vector and carries out gene knockout when transformed via conjugation by E. coli WM3064. However, the system is incapable of gene expression in Shewanella (Yin et al. 2013). For further genetic studies in Shewanella, it is important to have reliable plasmid based expression vectors. The term "plasmid" was proposed for the first time in 1952, regarding to any heritable elements independent of chromosomal DNA (Lederberg 1952). Plasmids consist of several basic elements including origin of replication (ori), promoter, insertion gene, antibiotic resistance, multiple cloning sites, and some additional genes. In particular, the ori region is essential for replication and maintenance of the plasmid in the cells, and promoter is required for gene expression. Thus, an appropriate ori is required for Shewanella to maintain the plasmid efficiently.

On the other hand, promoter element, which is essential for transcription of a gene, plays a critical role in controlling the expression level of downstream genes (Jana and Deb 2005). There are very few reports referring to recombinant expression in Shewanella currently. The heterologous expression of the $u d p$ genes from $S$. oneidensis MR-1 has been reported (Mordkovich et al. 2012, 2013). Besides, the promoter, tac, coupled with a synthetic flavin biosynthesis pathway from Bacillus subtilis has been shown to enhance extracellular electron-transfer (EET) rate of S. oneidensis MR-1 (Yang et al. 2015). Recently, we observed that promoter pLacI (R0010) combined with RBS (B0034), which was designed by iGEM, was activated efficiently in S. oneidensis MR-1. The RBS (B0034) was shown to have an efficiency of 1.0 and more detailed information is available on the website (http://parts.igem.org/ Part:BBa_B0034). The gene sequence encoding pLacI was amplified from lacZYA operon of E. coli MG1655 genome. So far, pLacI has been widely used for general recombinant expression in E. coli (http://parts .igem.org/Part:BBa_R0010). As E. coli and Shewanella are Gram negative bacteria, it is possible that pLacI has a great potential to be a common promoter for the expression of exogenous gene in Shewanella.

In the previous study, repB from pSXM33 has been explored in $S$. xiamenensis $\mathrm{BC} 01$ and considering its propagation in S. oneidensis MR-1 (Zhou and Ng 2016). It has been ensured that pSXM33 is retained for cell division in Shewanella. In this study, the transformation efficiency of plasmids harboring various replication origins for Shewanella was evaluated. First, we developed a functional ori for stable replication of plasmids in Shewanella. Several promoters were also tested for $g f p$ gene expression in Shewanella. Finally, we provided a proof-of-concept by combining repB and placI for expression of GFP gene in Shewanella, and followed by demonstrated expression of Mtr pathway as a proof-of-function in enhancement of ferric (Fe) reductase activity in MR-1.

\section{Methods}

Construction of recombinant plasmids for GFP expression

Bacterial strains, plasmids, and primers used in this study are given in Additional file 1: Table S1. Reagents used for plasmids construction including Ex-Taq polymerase, PCR-grade dNTPs, restriction enzyme, T4 ligase, and DNA ladder marker were purchased from Takara (Japan), while Phusion polymerase used for POE-PCR was obtained from NEB (USA). All DNA manipulations were performed according to standard protocols. PCR products and restriction-digested DNA were purified with PCR clean-up and gel extraction kits (GeneDirex, USA). The plasmids were isolated using Plasmid Extraction Mini Kit (Favorgen, Taiwan). Genomic DNA was isolated from $5 \mathrm{~mL}$ cells (overnight culture at $37{ }^{\circ} \mathrm{C}$ in LB broth) using a bacterial genomic DNA miniprep Kit (Axygen, USA). A recombinant plasmid denoted as pSB1C3-repB-GFP was constructed (Additional file 1: Fig. S1A). The gene sequence of $\operatorname{rep} B$ was amplified from plasmid pSXM33. After PCR, the DNA fragment was digested with PstI/SpeI, followed by ligating into pSB1C3-GFP. Three recombinant expression vectors for GFP expression with the same backbone and different promoters, including pETSXM2-proA-GFP, pETSXM2-proB-GFP, and pETSXM2-pLacI-GFP were also constructed (Additional file 1: Fig. S1B). The promoters (proA and proB) were amplified from plasmid pSXM33 and subsequently assembled with $g f p$ via fusion PCR. The gene fragments encoding GFP and pLacI-GFP were amplified from plasmid pSB1C3-GFP. Afterwards, the DNA fragments of proA-GFP, proB-GFP, and pLacI-GFP were digested with $\mathrm{XhoI} /$ PstI and inserted into plasmid Multi-pETSXM2.

\section{Construction of Mtr pathway genes}

The plasmids for recombinant expression of Mtr pathway genes, including pETSXM2-pLacI-MtrA, pETSXM2-pLacI-MtrC, and pETSXM2-pLacI-MtrCAB 
containing genes $m \operatorname{tr} A, m \operatorname{tr} C$, and $m \operatorname{tr} C A B$ respectively, were constructed using Prolonged Overlap Extension PCR (POE-PCR) (You and Zhang 2014) and the results are shown in Additional file 1: Fig. S1C. The genes that encoded MtrCAB are clustered in the sequential order $m \operatorname{tr} C$, $m$ tr $A$, and $m t r B$ in S. xiamenensis BC01 (BCRC 80958) genome. All the POE-PCR products were transformed into E. coli strains DH5 $\alpha$ and BL21(DE3), respectively. Recombinant colonies grown on LB plates with $50 \mu \mathrm{g} / \mathrm{mL}$ of kanamycin were confirmed by colony PCR. Then the correct plasmid constructs were isolated and transformed into S. oneidensis MR-1 via electroporation.

\section{Transformation into Shewanella via electroporation}

Plasmids were transformed into S. oneidensis MR-1 via electroporation as described previously with some modifications (Nováková et al. 2013; Rachkevych et al. 2014). Aerobically grown, mid-log phase cells at $\mathrm{OD}_{600 \mathrm{~nm}}$ of $0.5-0.8$ were chilled on ice about $20-30 \mathrm{~min}$ and harvested by centrifugation at $4000 \times g, 4{ }^{\circ} \mathrm{C}$ for $10 \mathrm{~min}$. The pellets were washed twice with half of the volume ice-cold sterile water and centrifuged at the above conditions, then suspended in distilled water to the final $\mathrm{OD}_{600 \mathrm{~nm}}$ at $125-200$. The obtained competent cells were poured into aliquots of $50 \mu \mathrm{L}$ in sterile microtubes. The competent cells were mixed with $0.4 \mu \mathrm{g}$ of plasmid DNA, transferred into precooled electroporation cuvette $(0.2 \mathrm{~cm})$ and electroporated for $5 \mathrm{~ms}$ at $2.5 \mathrm{kV}$ using MicroPulser ${ }^{\mathrm{TM}}$ electroporation apparatus (Bio-Rad, USA). After electroporation, $0.95 \mathrm{~mL}$ SOC medium $(2 \%(w / v)$ tryptone, $0.5 \%(w / v)$ yeast extract, $0.05 \%(w / v) \mathrm{NaCl}, 2.5 \mathrm{mM} \mathrm{KCl}, 10 \mathrm{mM} \mathrm{MgCl} 2,20 \mathrm{mM}$ glucose) was added to the cuvette immediately. The cells were quickly and gently suspended, transferred to culture tubes and incubated at $30{ }^{\circ} \mathrm{C}$ for $2 \mathrm{~h}$ or longer. Appropriate concentration was spread on LB agar plate containing the $25 \mu \mathrm{g} / \mathrm{mL}$ of chloramphenicol, $50 \mu \mathrm{g} /$ $\mathrm{mL}$ of kanamycin or $100 \mu \mathrm{g} / \mathrm{mL}$ of ampicillin, respectively. The plates were incubated at $30{ }^{\circ} \mathrm{C}$ for $24-36 \mathrm{~h}$. Screening of colonies for identification of positive cases were confirmed by restriction digestion of the isolated plasmids.

\section{Culture conditions}

Shewanella oneidensis MR-1 was aerobically cultivated in LB broth $(0.5 \%(w / v)$ yeast extract, $1 \%(w / v)$ tryptone, $1 \%(w / v) \mathrm{NaCl})$, or in a modified defined medium (MDM; $30 \mathrm{mM}$ Pipes, $60 \mathrm{mM}$ sodium DL-lactate, $28 \mathrm{mM}$ $\mathrm{NH}_{4} \mathrm{Cl}, 1.34 \mathrm{mM} \mathrm{KCl}, 4.35 \mathrm{mM} \mathrm{NaH} \mathrm{PO}_{4}, 7.5 \mathrm{mM}$ $\mathrm{NaOH}, 30 \mathrm{mM} \mathrm{NaCl}, 1 \mathrm{mM} \mathrm{MgCl}{ }_{2}$, and $0.05 \mathrm{mM}$ ferric nitrilotriacetic acid) (Pirbadian et al. 2014) at pH 6.5 and $30^{\circ} \mathrm{C}$ with constant shaking at $150 \mathrm{rpm}$. E. coli DH5 $\alpha$ and
BL21(DE3), the cloning hosts were incubated in LB broth at $\mathrm{pH} 7$ and $37^{\circ} \mathrm{C}$ with constant shaking at $200 \mathrm{rpm}$. A single colony was picked from LB agar plate and grown overnight with $3-5 \mathrm{~mL} \mathrm{LB}$, then $1 \%(v / v)$ broth was transferred into fresh LB broth. S. oneidensis MR-1 and E. coli transformants were selected on LB plates supplemented with the following relevant antibiotics: $25 \mu \mathrm{g} / \mathrm{mL}$ of chloramphenicol, $50 \mu \mathrm{g} / \mathrm{mL}$ of kanamycin, and $100 \mu \mathrm{g} /$ $\mathrm{mL}$ of ampicillin, respectively.

\section{Fluorescence analysis by fluorescent inverted microscope}

The culture of $S$. oneidensis MR-1 harboring different recombinant plasmids was diluted into $\mathrm{OD}_{600 \mathrm{~nm}}$ of 1.5 by centrifugation and resuspension. The cells were observed using Inverted Microscope (Nikon Eclipse, Japan) with Plan Fluor $40 \times$ Ph2 DLL Phase Contrast Eclipse Microscope Objective (Nikon, Japan) and imaged using Charge-coupled Device CoolSNAP HQ2 (Photometrics, USA). All the operations were conducted according to the instructions and captured at the excitation wavelength 465-495 $\mathrm{nm}$.

\section{Fe reductase assay by ferrozine}

Fe reductase assay was carried out under micro-anaerobic condition, which meant all the reagents were degassed for $10 \mathrm{~min}$ before use. The ferrozine combined with Fe(II) and formed purple complex and the absorbance of the complex was measured at $562 \mathrm{~nm}$ with modification (Stookey 1970). The activity of Fe reductase was calculated based on the rate of increasing absorbance at $562 \mathrm{~nm}\left(\varepsilon_{562 \mathrm{~nm}}=2.9 \times 10^{4} \mathrm{M} / \mathrm{cm}\right)$. The $200-\mu \mathrm{L}$ reaction mixture contained $90 \mu \mathrm{L}$ of $50 \mathrm{mM}$ sodium phosphate buffer (pH 7.0), $40 \mu \mathrm{L}$ of $2 \mathrm{mM}$ Fe-citrate, $10 \mu \mathrm{L}$ of $2 \mathrm{mM}$ ferrozine and $40 \mu \mathrm{L}$ of $10 \mathrm{mM}$ sodium formate and $20 \mu \mathrm{L}$ of cell culture at OD 3. The mixture sample was measured every $3 \mathrm{~min}$ for total $2 \mathrm{~h}$ via SpectraMax 340PC-384 (Molecular Devices, USA). All experiments were performed in triplicate independently.

\section{Native-PAGE analysis heme staining}

The cells harboring different recombinant plasmids were grown overnight and harvested by centrifugation at $8000 \times g$ for $10 \mathrm{~min}$. The cell pellets were washed with deionized water twice and re-suspended in deionized water to $\mathrm{OD}_{600 \mathrm{~nm}}$ of 4 . One volume cell was immersed in $20 \%(w / v)$ sucrose in $0.1 \mathrm{M}$ Tris-EDTA for $20 \mathrm{~min}$ at $4{ }^{\circ} \mathrm{C}$ to exclude the periplasma (P). The pellets were collected by centrifugation at 12,000 rpm for $10 \mathrm{~min}$ and resuspended in deionized water and followed by high-press disruption (One Shot, Constant systems, UK) to obtain the supernatant (S). Protein dye (SD6032, Sangon, China) without DTT was used in running the native-PAGE with $10 \%$ poly-acrylamide. The heme staining protocol was 
modified as reported previously (Thomas et al. 1976). In brief, all the process was performed in the dark. First, the gel was soaked in $0.25 \mathrm{M}$ sodium acetate $(\mathrm{pH} 5)$ for $20 \mathrm{~min}$ and then $15 \mathrm{~g} / \mathrm{L}$ of 3,3',5,5'-tetramethylbenzidine (TMBZ, Sigma) dissolved in methanol was added. The gel was allowed to soak in the solution in an orbital shaker at $70 \mathrm{rpm}$ for $15 \mathrm{~min}$. The proteins were visualized by adding $200 \mu \mathrm{L}$ of $30 \%(v / v)$ hydrogen peroxide within $30 \mathrm{~min}$.

\section{Protein identification by MALDI-TOF-TOF and MASCOT}

The MALDI-TOF-TOF analyses were performed in positive ionization mode using an AB SCIEX TOF/TOF 5800 System (Applied Biosystems, USA). The method was performed regarding to previous study with some modification (Ng et al. 2014a, b). The protein was first digested by $1 \%(w / v)$ trypsin overnight and the digested protein was recovered by lyophilization. Peptide was loaded into the instrument by accelerating voltages of 20 and $8 \mathrm{kV}$ which was used for MS/MS measurements. Raw spectral data were further processed using Data Explorer 4.6 software (Applied Biosystems, USA) and followed by MASCOT analysis.

\section{Plasmid stability assay}

The plasmid stability analysis was performed as described previously with some modifications (Ashiuchi et al. 1999). Cells harboring different plasmids were grown and sub-cultured in LB medium until the total number of generations had reached 90 . When the number of generation had reached 30,60 , and 90 , the cell culture was spread on LB plates both with and without appropriate resistance. After $12 \mathrm{~h}$ incubation at $30^{\circ} \mathrm{C}$, colonies (CFU) were counted and the ratio of antibiotic resistant colonies to the total number of colonies was used to estimate the percentage of cells maintaining the plasmid. All experiments were performed in triplicate independently.

\section{Results and discussion}

Importance of resistance and replication origin in Shewanella

Plasmids used in Shewanella are summarized in Table 1. Saffarini and Nealson reported that plasmid pACYC18 containing the p15A ori can't replicate in S. oneidensis MR-1 (Saffarini and Nealson 1993). However, the above conclusion was contradicted by Myers, who proved that pACYC18 could independently replicate in MR-1 (Myers and Myers 1997). In addition, it is worth mentioning that pUC vector or pUC-derived vector functioned well in S. oneidensis (Nováková et al. 2013; Ozawa et al. 2001). Recently, some of ColE1-type plasmids (i.e., pBR328; pECFP-c1; pZA31; pZE21), pSC101 ori plasmids (i.e., pHM1884; pZS24luc) and P1 phage-derived plasmid (i.e., pSP102) could be transformed into S. baltica
(Milewska et al. 2015). Therefore, ColE1-type plasmids mainly with the well-known origins of ColE1, pMB1, and p15A could be adapted for plasmids to be used in Shewanella. However, another plasmid pWUZ1 harboring ColE1 origin could not replicate in S. baltica under tetracycline selective pressure (Studier et al. 1990). Coincidentally, pACYC18 transformants could not be isolated under tetracycline selective pressure (Myers and Myers 1997), but few ampicillin-resistant $\left(\mathrm{Ap}^{\mathrm{R}}\right)$ transformants were obtained (Ozawa et al. 2001). The data indicated that it was very difficult to express tetracycline resistance gene for achieving tetracycline resistance in Shewanella genus. As a conclusion, selection of an appropriate antibiotic resistance gene as a selection marker that can be expressed in Shewanella can aid in easier selection of transformants and achieve higher efficiency of transformation.

To deeply explore various replication ori which is suitable for S. oneidensis MR-1, we use several vectors with different types of ori. The information of origin, size, antibiotic resistance, and efficiency of transformation are shown in Table 1 and Fig. 1. The result of pBAD33 with p15A ori is consistent with previous study (Ozawa et al. 2001). The plasmid pSFKW33 from Shewanella sp. 33B (Werbowy et al. 2009), and plasmid pSXM33 from S. xiamenensis BC01 (Zhou and Ng 2016) with ori of $\mathrm{R}-6 \mathrm{~K}$ like and repB are function in different kinds of Shewanella. Moreover, we further confirmed that PCRISPRCas9 with p15A (ori) and pBluescript-SK(II) with pUC (ori) can be introduced into MR-1 (Fig. 1). As aforementioned, we have constructed two shuttle vectors for $E$. coli and Shewanella (i.e., pETSXM1 and pETSXM2) on the basis of the ori rep $\mathrm{B}$ from $\mathrm{pSXM} 33$, and ori $\mathrm{pMB} 1$ from pET28a(+) (Zhou and Ng 2016). We observed that the plasmids pETSXM1 and pETSXM2 could be transformed into MR-1, but pET28a(+) could not. It showed that repB played a decisive role and directed replication independently. As pETSXM2 (3364 bp) showed a 16-fold higher efficiency of transformation than pETSXM1 (6898 bp), it is indicated that the size of plasmid for transformation was critical. Notably, the vector pSB1C3-repB with rep B ori has much higher transformation efficiency (i.e., 1000 colony foaming units) than the parental plasmid pSB1C3 (only 6-8 colony foaming unit), suggesting that $r e p B$ positively influenced the replication and maintenance of plasmids in Shewanella.

\section{Promoter effect on GFP expression}

The promoter $p r o A$ and $p r o B$ from the plasmid pSXM33 were identified as hypothetical promoters (Zhou and $\mathrm{Ng}$ 2016), while the promoter pLacI have been widely used in E. coli. Herein, we found that only promoter pLacI could drive the expression of GFP in S. oneidensis MR-1 among 
Table 1 Transformation of Shewanella species with vectors contained a diverse array of origin, size and antibiotic resistance

\begin{tabular}{|c|c|c|c|c|c|c|}
\hline Strain & Vector & Ori & Size (bp) & $R^{a}$ & $T^{\mathbf{b}}$ & References \\
\hline \multirow[t]{8}{*}{ S. baltica } & pHM1884 & pSC101 & 4235 & $\mathrm{Spc}$ & No & Milewska et al. (2015) \\
\hline & pZS24luc & pSC101 & 5583 & Kan & No & \\
\hline & pBR328, & ColE1-like, pMB1 & 4907 & $\mathrm{Cm}$, Tet & Yes & \\
\hline & pECFP-c1 & ColE1-like, pMB1 & 4700 & Kan & Yes & \\
\hline & pZA31 & ColE1-like, p15A & 3666 & $\mathrm{Cm}$ & Yes & \\
\hline & pZE21 & ColE1-like, ColE1 & 3832 & Kan & Yes & \\
\hline & pWUZ1 (tertR) & ColE1-like, ColE1 & 4683 & Tet & No & \\
\hline & pSP102 & Bacteriophage P1 & 4254 & $\mathrm{Cm}$ & Yes & \\
\hline S. putrefaciens MR- $1^{*}$ & pACYC184 & p15A-based & 4245 & Tet, $\mathrm{Cm}$ & No & Saffarini and Nealson (1993) \\
\hline \multirow[t]{2}{*}{ S. putrefaciens MR- $1^{*}$} & pACYC184 & p15A-based & 4245 & Tet, $\mathrm{Cm}$ & Yes & Myers and Myers (1997) \\
\hline & pBR322 & $\mathrm{pMB1}$ & 4361 & Amp, Tet & No & \\
\hline S. oneidensis TSP-C & $\mathrm{pMC}^{* *}$ & pUC-type & - & Rifampicin Tet & Yes & Ozawa et al. (2001) \\
\hline Shewanella sp. 33B & pSFKW33 & R-6 K like & 8021 & ND & No & Werbowy et al. (2009) \\
\hline \multirow[t]{3}{*}{ S. oneidensis MR-1 } & pUC-kanMX & pMB1 & - & Kan, Amp & Yes & Rachkevych et al. (2014) \\
\hline & pBR322 & pMB1 & 4361 & Amp, Tet & Yes & \\
\hline & pBAD33 & p15A-based, f1 & 5352 & $\mathrm{Cm}$ & Yes & \\
\hline \multirow{8}{*}{ S. oneidensis MR-1 } & pBAD33 & f1, p15A & 5352 & $\mathrm{Cm}(12.5)$ & Yes & This study \\
\hline & pBluescript-SK(-) & $f 1, p \cup C$ & 2961 & Amp (100) & Yes & This study \\
\hline & pCRISRP-Cas9 & p15A & 9362 & $\mathrm{Cm}(12.5)$ & Yes & This study \\
\hline & pETSXM1 & $\mathrm{f1}, \mathrm{pBR} 322$, repB & 6898 & Kan (50) & Yes & This study \\
\hline & pETSXM2 & $\mathrm{f1}, \mathrm{pBR322,}$ repB & 3364 & Kan (50) & Yes & This study \\
\hline & pSB1C3-GFP & pMB1 & 3153 & $\mathrm{Cm}(25)$ & Yes & This study \\
\hline & pSB1C3-repB(SXM)-GFP & pMB1, repB & 4219 & $\mathrm{Cm}(25)$ & Yes & This study \\
\hline & pKD46 & R101, repA101ts & 6329 & $\operatorname{Amp}(100)$ & No & This study \\
\hline
\end{tabular}

ND not determined

* S. putrefaciens MR-1 has been later reclassified as S. oneidensis MR-1 (Heidelberg et al. 2002)

** Derived from pUC119

a $R$ means resistance of antibiotic

b T means transformants

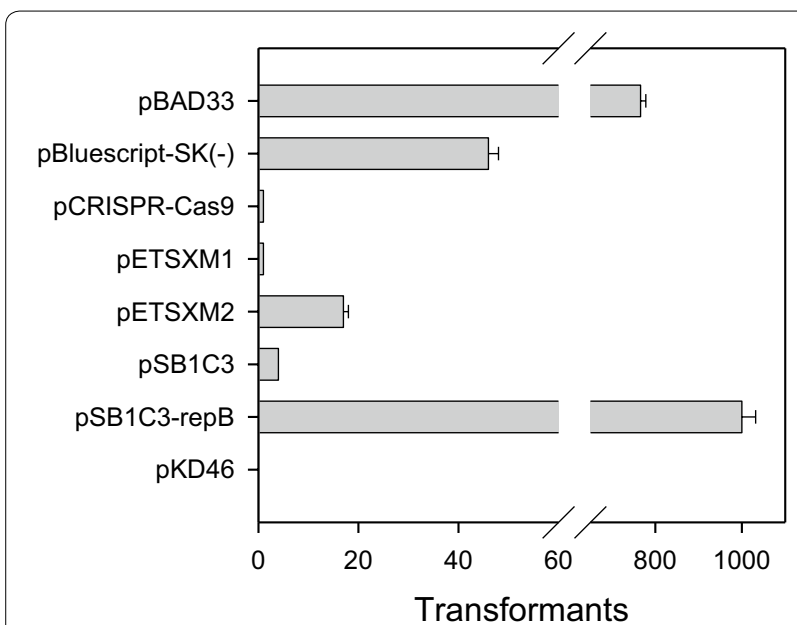

Fig. 1 Transformants in MR-1 with different vectors. The transformants are counted by colony foaming unit (CFU) after electroporation to MR-1 the above mentioned promoters. As shown in Table 2, all the cells carrying different recombinant plasmids with the same promoter (i.e., pLacI) expressed GFP successfully under pLacI. Besides, the order of CFU is ranking from pSB1C3-repB > pETSXM2-placI, pETSXM2-proA, pETSXM2-proB, and pSB1C3 (in numbers: 1000, 888, 358,288 , and 4 ). The cells carrying recombinant plasmids with the promoter proA and proB preserved the red color that was the original color of MR-1. The results were consistent with SDS-PAGE analysis (Fig. 2). The cells harboring recombinant plasmids with pLacI as promoter, including pETSXM2-placI-GFP, pSB1C3-GFP, and pSB1C3-repB-GFP, had a clear band at $26 \mathrm{kDa}$ representing GFP. In addition, the fluorescence of GFP could be observed via fluorescent inverted microscope from the cells harboring pETSXM2-placI-GFP, pSB1C3-GFP, and pSB1C3-repB-GFP, respectively (Fig. 2b). Thus, promoter 
Table 2 Transformation of S. oneidensis MR-1 for over-expression of GFP with different ori and promoter

\begin{tabular}{|c|c|c|c|c|c|c|}
\hline Plasmids & Ori & Size (bp) & Resistance & CFU result & GFP function & Culture picture \\
\hline pETSXM2-pLacl-GFP & f1, pBR322, repB-SXM & 4626 & Kan (50) & 888 & Yes & \\
\hline pETSXM2-proA-GFP & f1, pBR322, repB-SXM & 4290 & Kan (50) & 358 & No & \\
\hline pETSXM2-proB-GFP & f1, pBR322, repB-SXM & 4395 & Kan (50) & 288 & No & \\
\hline pSB1C3-repB-GFP & pMB1, repB-SXM & 4219 & Cm (25) & 1000 & Yes & \\
\hline pSB1C3-GFP & pMB1 & 3153 & $\mathrm{Cm}(25)$ & 4 & Yes & \\
\hline
\end{tabular}

pLacI enabled successful gene expression both in E. coli and S. oneidensis MR-1.

As the proA and proB are hypothetical promoters as predicted by the gene prediction software Softberry (http://www.softberry.com/), it is implied that the non-functional nature of those hypothetical promoters prediction should present more constraints in gene expression. The possibility of a functional upstream or downstream transcription region with these two promoters is uncertain. Thus, the authenticity and applicability of proA and proB for Shewanella requires further investigation. The pLacI promoter sequence with original length of $200 \mathrm{bp}$, consists of $88 \mathrm{bp}$ of the end of lacI repressor region, CAP binding site, lacI binding site and the natural promoter for lacZYA gene. As pLacI is constitutive when the lac repressor (lacI or lacIq) and CAP protein are absent, it should be a powerful promoter which can activate both in Shewanella and E. coli, and the transcription machinery of pLacI is relatively simple. To the best of our knowledge, this is the first report for expression of GFP in Shewanella by pLacI.

\section{Recombinant Mtr pathway enhanced Fe reductase activity} in MR-1

Several plasmids, (i.e., $m \operatorname{tr} A, m \operatorname{tr} C$, and $m \operatorname{tr} C A B$ into plasmid pETSXM2), which overexpressed the $M t r$ genes under the promoter pLacI and repB was constructed in S. oneidensis MR-1. The plasmids were confirmed by agarose electrophoresis and DNA sequencing. The size of $m t r \mathrm{~A}, m t r \mathrm{C}$, and $m \operatorname{tr} \mathrm{CAB}$ were 4902, 5886, and $9062 \mathrm{bp}$, 


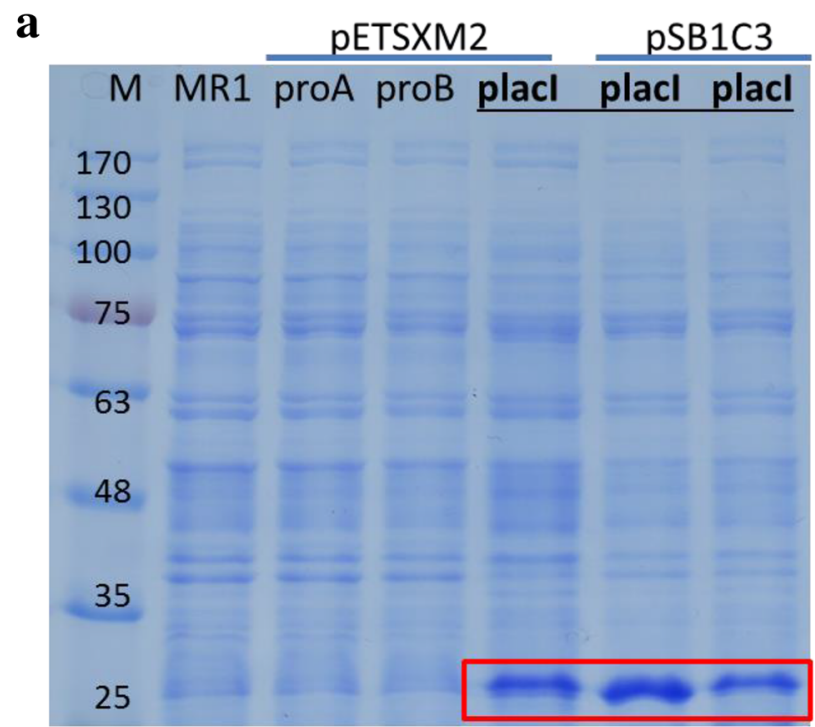

\section{b}

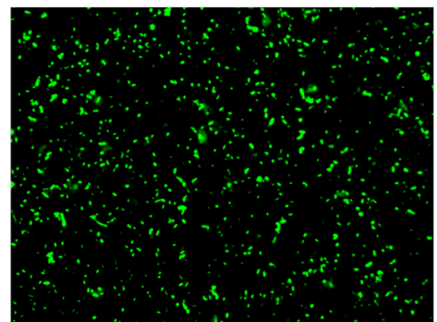

pETSXM2-pLacI-GFP

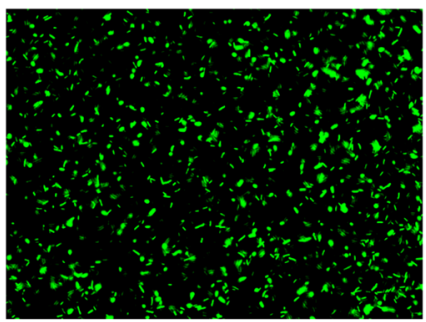

pSB1C3-repB-GFP

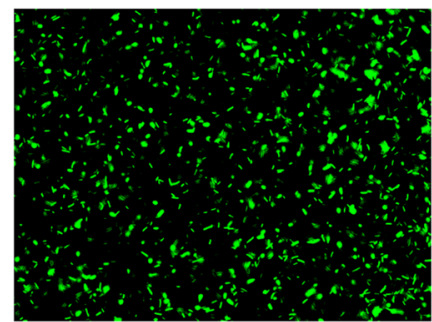

pSB1C3-GFP

Fig. 2 a SDS-PAGE analysis of over-expression of GFP in S. oneidensis MR-1. Lanes from left to right: Marker, MR-1 wild type, pETSXM2-proA, pETSXM2-proB, pETSXM2-pLacl, pSB1C3-repB-pLacl and pSB1C3-pLacl. b Cell pictures in $\times 40$ Nikon inverted florescence microscope at excitation 465-495 nm. From left to right are pETSXM2-pLacl-GFP, pSB1C3-repB-GFP and pSB1C3-GFP, respectively

respectively (Fig. 3a). The expression-level analysis of these genes by heme staining in Native-PAGE was performed (Fig. 3b). From the plasmids harboring $m t r$ genes, a significant band with a molecular weight near $70 \mathrm{KDa}$ was observed. It was predicted as the cytochrome $\mathrm{c}$ (MtrC) by MASCOT protein identification (Table 3). Furthermore, MR-1 with the plasmids pETSXM2-placI harboring $m t r A, m t r C$, and $m t r C A B$ had higher ferric reductase than that of the wild strain. Among all, the $m t r C$ strain had highest ferric reductase activity of $508.33 \mathrm{U} / \mathrm{L}$, which was $153 \%$ as of wild strain (Fig. 3c). The activity was followed by strains with gene of $m$ tr$\mathrm{CAB}$, mtrA, and wild type, in terms of $412.5,391.4$, and $345.1 \mathrm{U} / \mathrm{L}$, respectively. Moreover, biomass for different strains was similar, at $3.5 \mathrm{~g} / \mathrm{L}$. As we knew, MtrA, located in the periplasm of MR-1 was considered as an important gene for Fe(III) and Mn(IV) reduction (Beliaev et al. 2001). The MtrB located in the outer-membrane of MR-1 aided $\mathrm{MtrC}$ in metal binding for reduction (Beliaev and
Saffarini 1998). And MtrC, found in the outer-membrane played an important role in Fe(III) reduction. Mtr pathway allowed electron transport from the cell interior to the extracellular inorganic material. Based on the result of Fig. 3b, c, it indicated that enhancing Mtr pathway via recombinant expression of $m t r$ gene under the promoter pLacI was successful.

\section{Culture effect and Plasmid stability}

The four recombinant strains had different growth rates in LB and MDM medium (Fig. 4). The wild strain had the highest growth rate, and the $m t r C A B$ strain had the lowest growth rate, while the $m t r \mathrm{~A}$ and $m t r \mathrm{C}$ strain had analogous growth trends. As larger plasmid size would burden cell growth, the strain with mtrCAB had lower growth rate. In the previous study (Pirbadian et al. 2014), it was observed that minimal or defined medium was beneficial to Shewanella in oxido-reduction with sodium DL-lactate as the major elector donor. In the 
a

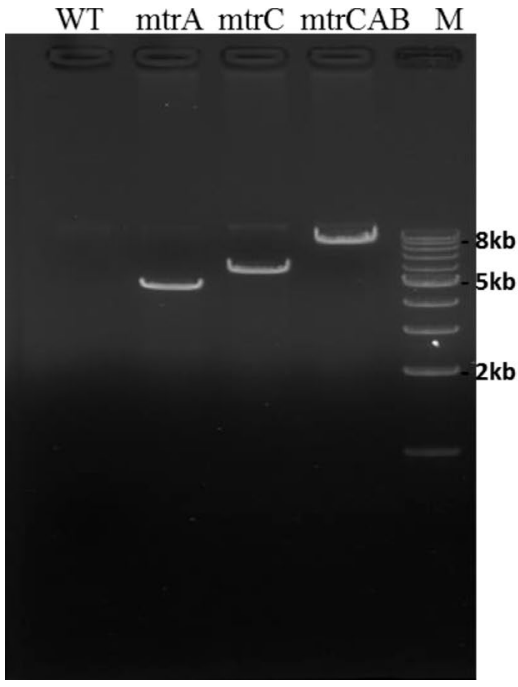

b
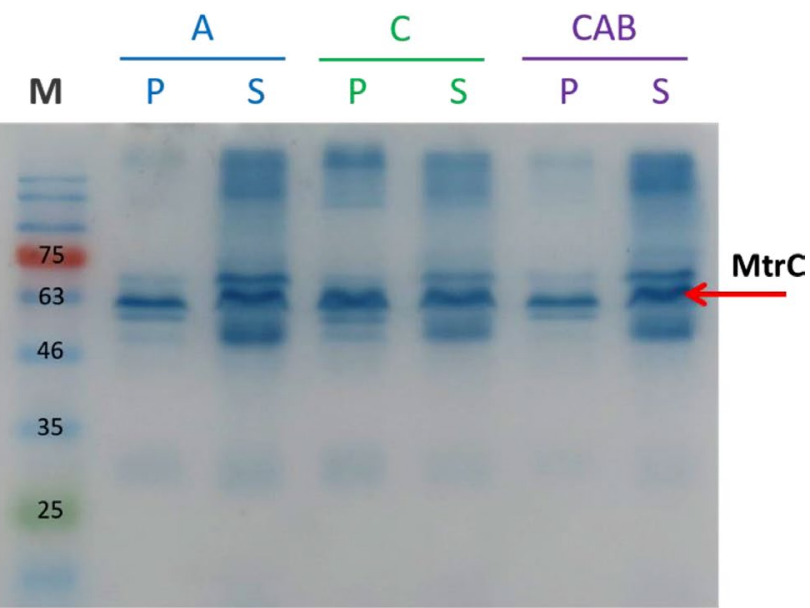

C

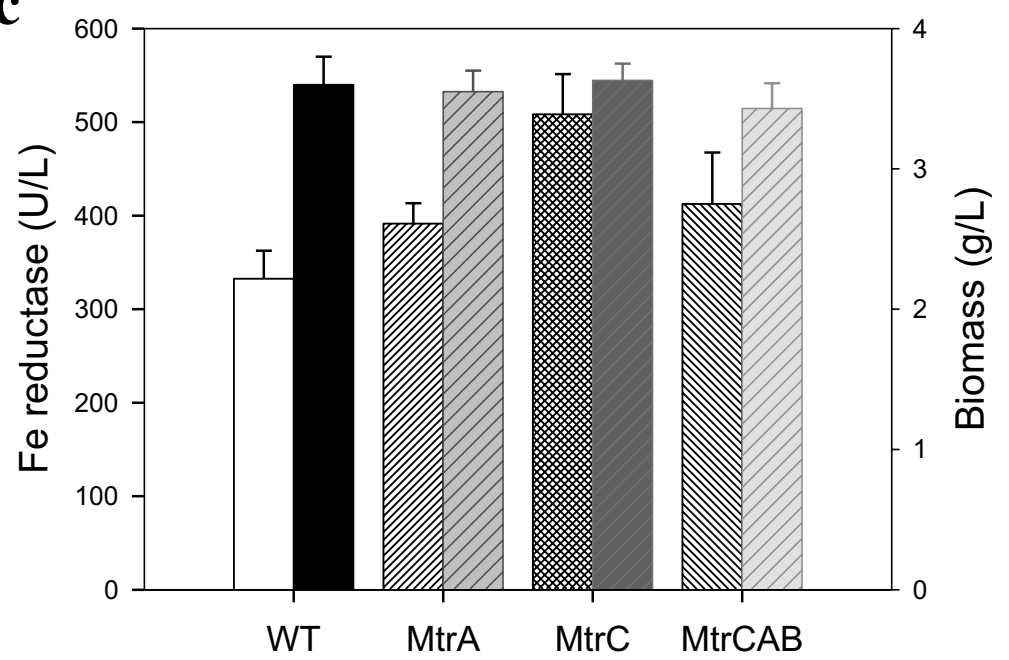

Fig. 3 a Confirmation of plasmids in wild type of MR1, $m$ trA, $m$ tr $C$ and $m t r C A B$ by $0.8 \%$ agarose gel. $\mathbf{b}$ Heme staining activity of cells harboring of $m$ trA, $m$ tr $C$ and $m$ trCAB genes. Cell harvest at $24 \mathrm{~h}$ and concentrated to OD 4. P and S mean pellet and supernatant. $\mathbf{c}$ Left bars are ferric reductase activity and right bars are biomass of wild type of MR1, $m$ trA, $m$ trCAB and $m$ tr $C$

Table 3 MASCOT protein identification of Shewanella oneidensis MR-1 from heme staining

\begin{tabular}{|c|c|c|c|c|c|c|}
\hline Sample & Protein name & Strain species & Protein score & Accession no & $M w(D a)$ & $\mathrm{pl}$ \\
\hline MR1-mtrCAB & Cytochrome c MtrC & S. oneidensis MR-1 & 269 & WP_011071901 & 71,232 & 5.68 \\
\hline
\end{tabular}

absence of oxygen, Shewanella grew by coupling the oxidation of simple organic acids, alcohols, or aromatic compounds to the reduction of $\mathrm{Fe}(\mathrm{III})$ or $\mathrm{Mn}$ (IV). In this study, we first analyzed cell growth in a modified defined medium (MDM) and LB medium. As shown in Fig. 4, the cell growth among all strains was higher in
LB medium than that in MDM. We also observed that there was no significant difference in ferric reductase activity when the strains were grown in MDM or LB (data not shown). In MDM medium, the cell growth of all strains became slower during the late phase (i.e., $600 \mathrm{~min}$ ) because of insufficient nutrition. In summary, 

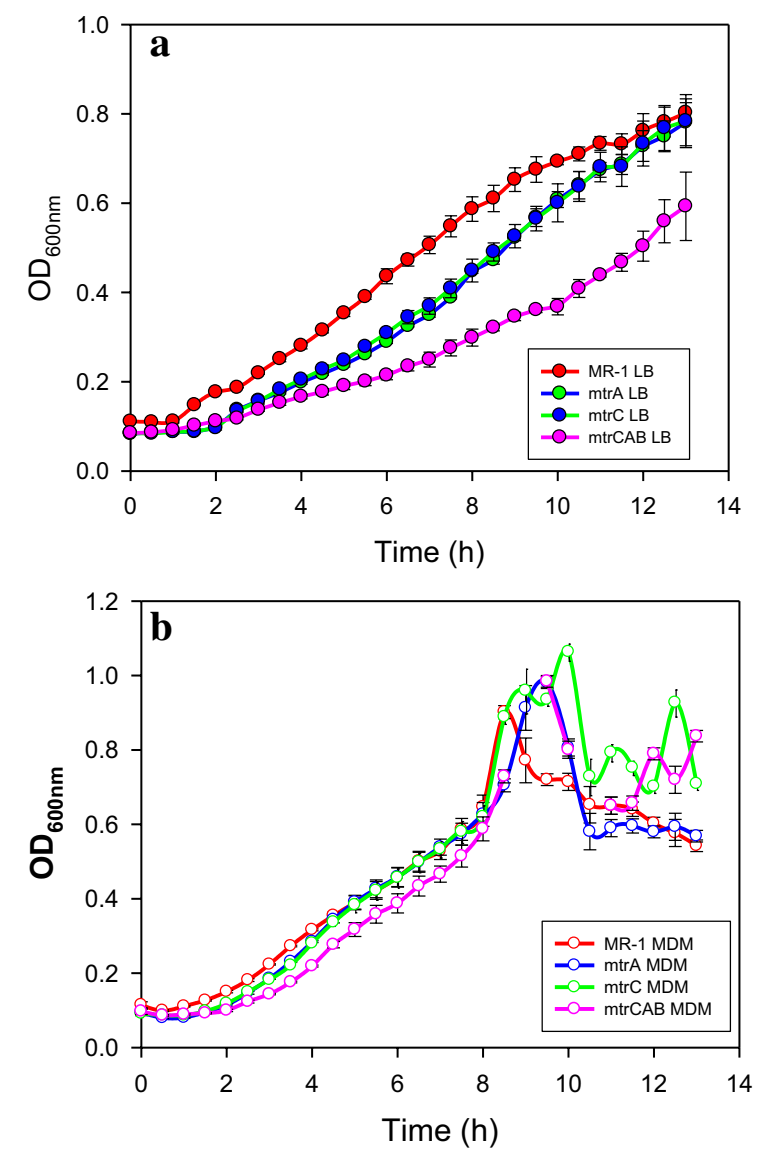

Fig. 4 Cell growth in a LB and b MDM medium. (red) Wild type MR-1, (blue) $m$ trA, (green) $m t r C$, and (pink) $m t r C A B$ genetic strains

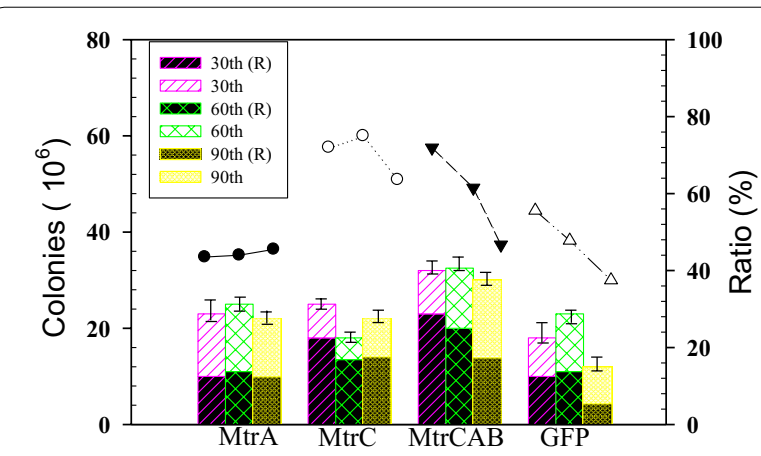

Fig. 5 Plasmid stability analysis for MtrA, MtrC, MtrCAB and GFP in terms of colonies shown in black bar for culture in antibiotics, white stack-bar for culture without antibiotics (left $Y$-axis), and the ratio (right Y-axis) of (black circle) MtrA, (open circle) MtrC, (black diamond) MtrCAB and (open diamond) GFP

LB medium is required in long term fermentation while MDM is preferred in short term culture as it is much cost effective.
Plasmid stability analysis was performed by analyzing colonies forming units (CFU) in the presence and absence of antibiotics for all different strains as shown in Fig. 5. The three strains with plasmid pETSXM2placI $m t r \mathrm{~A}, m t r C$, and $m t r C A B$ exhibited high stability when the cell generation number reached 90 in the medium with (black bars) or without appropriate resistance (white stack-bars). But the colonies with plasmids harboring GFP showed a lower number, which trended down to $4.5 \times 10^{6}$ after 90 generations. The ratio of colonies between medium with and without resistance was around $75 \%$ for $\mathrm{MtrC}, 62 \%$ for $\mathrm{MtrCAB}, 1 \%$ for $\mathrm{Mtr} A$, and GFP in 90 generations (Fig. 5). The results indicated that the plasmid exist stably in the host cells. The ori region is required for plasmid self-replication while the size of the plasmid and the type of selective marker can influence the transformation efficiency, and plasmid stability is critical in genetic engineering. ColE1 is very stable under most growth conditions in Gram negative bacteria (Summers and Sherratt 1984). The plasmids with ori regions of ColE1, pMB1, and repB are shown to be relatively stable in Shewanella, comparable to other Gram negative bacteria (Kües and Stahl 1989). Herein, we found that repB from pSXM33 which originally existed in S. xiamenensis was stable and function in MR-1.

\section{Conclusion}

Genetic engineering in Shewanella is limited mainly due the lack of stable plasmids and reliable expression systems. We proved that ori repB from pSXM33 and pLacI promoter from E. coli is functional in S. oneidensis MR-1. Plasmid constructs with ori rep B had higher efficiency of transformation compared to others. The pLacI promoter was functional in S. oneidensis MR-1, driving the expression of GFP, which is reported for the first time. Based on the ori rep $\mathrm{B}$ and pLacI promoter, genes for the metal reducing pathway (MTR) were expressed in S. oneidensis MR-1 and the ferric reductase activity was improved in the recombinant strain.

\section{Additional file}

Additional file 1: Table S1. Bacterial strains, plasmids and primers used in this study. Fig. S1. Recombinant plasmids in this study. (A) The plasmid pSXM33 from S. xiamenensis BC01, and pSB1C3-GFP from iGEM were used to construct pSB1C3-repB-GFP for over-expression of GFP. (B) Different ori and promoters (proA, proB and placl). (C) Over-expression vectors harboring MtrA, MtrC and MtrCAB with repB and placl.

Authors' contributions

ISN and YZ designed the experiment and analyzed the data, $Y Z$ and $Y G$ performed most of experiments in genetic section. JWW, YCY and SIT did the 
enzymatic experiments. ISN and YG wrote the manuscript. All authors read and approved the final manuscript.

\section{Author details}

${ }^{1}$ Department of Chemical Engineering, National Cheng Kung University, Tainan 70101, Taiwan. ${ }^{2}$ Department of Chemical and Biochemical Engineering, Xiamen University, Xiamen 361005, China.

\section{Acknowledgements}

The authors are grateful for the financial support received for this project from the Ministry of Science and Technology (MOST 105-2221-E-006-225-MY3 and MOST 105-2621-M-006-012-MY3) in Taiwan. We also sincerely appreciate the academic connection between Xiamen University (China) and National Cheng Kung University (Taiwan).

\section{Competing interests}

The authors declare that they have no competing interests.

\section{Availability of data and materials}

The authors approved the availability of data and materials for publishing the manuscript.

\section{Consent for publication}

The authors approved the consent for publishing the manuscript.

\section{Ethics approval and consent to participate}

All the authors have read and agreed the ethics for publishing the manuscript.

\section{Publisher's Note}

Springer Nature remains neutral with regard to jurisdictional claims in published maps and institutional affiliations.

Received: 14 June 2018 Accepted: 20 July 2018

Published online: 25 July 2018

\section{References}

Ashiuchi M, Zakaria MM, Sakaguchi Y, Yagi T (1999) Sequence analysis of a cryptic plasmid from Flavobacterium sp. KP1, a psychrophilic bacterium. FEMS Microbiol Lett 170:243-249

Beliaev AS, Saffarini DA (1998) Shewanella putrefaciens mtrB encodes an outer membrane protein required for Fe(III) and Mn(IV) reduction. J Bacteriol 180:6293-6297

Beliaev AS, Saffarini DA, McLaughlin JL, Hunnicutt D (2001) MtrC, an outer membrane decahaem c cytochrome required for metal reduction in Shewanella putrefaciens MR-1. Mol Microbiol 39:722-730

Bretschger O, Obraztsova A, Sturm CA, Chang IS, Gorby YA, Reed SB, Culley DE, Reardon CL, Barua S, Romine MF, Zhou J, Beliaev AS, Bouhenni R, Saffarini D, Mansfeld F, Kim BH, Fredrickson JK, Nealson KH (2007) Current production and metal oxide reduction by Shewanella oneidensis MR-1 wild type and mutants. Appl Environ Microbiol 73:7003-7012

Chaturvedi V, Verma P (2016) Microbial fuel cell: a green approach for the utilization of waste for the generation of bioelectricity. Bioresour Bioprocess 3:38

Chen BY, Hong J, Ng IS, Wang YM, Liu SQ, Lin B, Ni C (2013) Deciphering simultaneous bioelectricity generation and reductive decolorization using mixed-culture microbial fuel cells in salty media. J Taiwan Inst Chem Eng 44:446-453

Heidelberg JF, Paulsen IT, Nelson KE, Gaidos EJ, Nelson WC, Read TD, et al (2002) Genome sequence of the dissimilatory metal ion-reducing bacterium Shewanella oneidensis. Nature Biotechnol 20:1118-1123

Jana S, Deb JK (2005) Strategies for efficient production of heterologous proteins in Escherichia coli. Appl Microbiol Biotechnol 67:289-298

Jayasinghe N, Franks A, Nevin KP, Mahadevan R (2014) Metabolic modeling of spatial heterogeneity of biofilms in microbial fuel cells reveals substrate limitations in electrical current generation. Biotechnol J 9:1350-1361
Jensen HM, Albers AE, Malley KR, Londer YY, Cohen BE, Helms BA, Weigele P, Groves JT, Ajo-Franklin CM (2010) Engineering of a synthetic electron conduit in living cells. Proc Natl Acad Sci USA 107:19213-19218

Kües U, Stahl U (1989) Replication of plasmids in Gram-negative bacteria. Microbiol Rev 53:491-516

Lederberg J (1952) Cell genetics and hereditary symbiosis. Physiol Rev 32:403-430

Milewska K, Węgrzyn G, Szalewska-Pałasz A (2015) Transformation of Shewanella baltica with ColE1-like and P1 plasmids and their maintenance during bacterial growth in cultures. Plasmid 81:42-49

Mordkovich NN, Manuvera VA, Veiko VP, Debabov VG (2012) Uridine phosphorylase from Shewanella oneidensis MR-1: heterological expression, regulation, transcription, and properties. Appl Biochem Micro 48:716-722

Mordkovich NN, Voeikova TA, Novikova LM, Smirnov IA, Soldatov PE, TyurinKuz'min AY, Smolenskaya TS, Veiko VP, Shakulov RS, Debabov VG (2013) Effect of $\mathrm{NAD}^{+}$-dependent formate dehydrogenase on anaerobic respiration of Shewanella oneidensis MR-1. Microbiology 82:404-409

Myers CR, Myers JM (1997) Replication of plasmids with the p15A origin in Shewanella putrefaciens MR-1. Lett Appl Microbiol 24:221-225

Nealson KH, Scott J (2006) Ecophysiology of the genus Shewanella. The prokaryotes. Springer, New York, pp 1133-1151

Ng IS, Chen T, Lin R, Zhang X, Ni C, Shun D (2014a) Decolorization of textile azo dye and Congo red by an isolated strain of the dissimilatory manganesereducing bacterium Shewanella xiamenensis BC01. Appl Microbiol Biotechnol 98:2297-2308

Ng IS, Zheng X, Wang N, Chen BY, Zhang X, Lu Y (2014b) Copper response of Proteus hauseri based on proteomic and genetic expression and cell morphology analyses. Appl Biochem Biotechnol 173:1057-1072

Ng IS, Hsueh CC, Chen BY (2017) Electron transport phenomena of electroactive bacteria in microbial fuel cells: a review of Proteus hauseri. Bioresour Bioprocess 4:53

Nováková J, Izsáková A, Grivalský T, Ottmann C, Farkašovský M (2013) Improved method for high-efficiency electrotransformation of Escherichia coli with the large BAC plasmids. Folia Microbiol (Praha) 59:53-61

Ozawa K, Yasukawa F, Fujiwara Y, Akutsu H (2001) A simple, rapid, and highly efficient gene expression system for multiheme cytochromes c. Biosci Biotechnol Biochem 65:185-189

Pirbadian S, Barchinger SE, Leung KM, Byun HS, Jangir Y, Bouhenni RA, Reed SB, Romine MF, Saffarini DA, Shi L, Gorby YA, Golbeck JH, Barchinger SE, El-Nagger MY (2014) Shewanella oneidensis MR-1 nanowires are outer membrane and periplasmic extensions of the extracellular electron transport components. Proc Natl Acad Sci USA 111:12883-12888

Rachkevych N, Sybirna K, Boyko S, Boretsky Y, Sibirny A (2014) Improving the efficiency of plasmid transformation in Shewanella oneidensis MR-1 by removing Clal restriction site. J Microbiol Methods 99:35-37

Saffarini DA, Nealson KH (1993) Sequence and genetic characterization of etrA, an fnr analog that regulates anaerobic respiration in Shewanella putrefaciens MR-1. J Bacteriol 175:7938-7944

Shi L, Rosso KM, Zachara JM, Fredrickson JK (2012) Mtr extracellular electrontransfer pathways in Fe(III)-reducing or Fe(II)-oxidizing bacteria: a genomic perspective. Biochem Soc Trans 40:1261-1267

Stookey LL (1970) Ferrozine-new spectrophotometric reagent for iron. Anal Chem 42:779-781

Studier FW, Rosenberg AH, Dunn JJ, Dubendorff JW (1990) Use of T7 RNA polymerase to direct expression of cloned genes. Method Enzynol 185:60-89

Summers DK, Sherratt DJ (1984) Multimerization of high copy number plasmids causes instability: ColE1 encodes a determinant essential for plasmid monomerization and stability. Cell 36:1097-1103

Takahashi S, Miyahara M, Kouzuma A, Watanabe K (2016) Electricity generation from rice bran in microbial fuel cells. Bioresour Bioprocess 3:50

Thomas PE, Ryan D, Levin W (1976) An improved staining procedure for the detection of the peroxidase activity of cytochrome P-450 on sodium dodecyl sulfate polyacrylamide gels. Anal Biochem 75:168-176

Werbowy K, Cieśliński H, Kur J (2009) Characterization of a cryptic plasmid pSFKW33 from Shewanella sp. 33B. Plasmid 62:44-49

Wu JW, Ng IS (2017) Bio fabrication of gold nanoparticles by Shewanella species. Bioresour Bioprocess 4:50 
Yang Y, Ding Y, Hu Y, Cao B, Rice SA, Kjelleberg S, Song H (2015) Enhancing bidirectional electron transfer of Shewanella oneidensis by a synthetic flavin pathway. ACS Synth Biol 4:815-823

Yin J, Sun L, Dong Y, Chi X, Zhu W, Qi SH, Gao H (2013) Expression of blaA

underlies unexpected ampicillin-induced cell lysis of Shewanella oneidensis. PLOS ONE 8:e60460

You C, Zhang YHP (2014) Simple cloning and DNA assembly in Escherichia coli by prolonged overlap extension PCR. Methods Mol Biol 1116:183-192
Yuan J, Wei B, Shi M, Gao H (2011) Functional assessment of EnvZ/OmpR twocomponent system in Shewanella oneidensis. PLoS ONE 6:e23701

Zhou Y, Ng IS (2016) Explored a cryptic plasmid pSXM33 from Shewanella xiamenensis BC01 and construction as the shuttle vector. Biotechnol Bioprocess Eng 21:68-78

\section{Submit your manuscript to a SpringerOpen ${ }^{\circ}$ journal and benefit from:}

- Convenient online submission

- Rigorous peer review

- Open access: articles freely available online

- High visibility within the field

- Retaining the copyright to your article

Submit your next manuscript at springeropen.com 